\title{
Effects of fasting on solid organ transplant recipients during Ramadan - a practical guide for healthcare professionals
}

\author{
Authors: Shafi Malik, ${ }^{\mathrm{A}}$ Rizwan Hamer, ${ }^{\mathrm{B}}$ Shazia Shabir, ${ }^{\mathrm{C}}$ Sajeda Youssouf, ${ }^{\mathrm{D}}$ Mohamed Morsy, ${ }^{\mathrm{E}}$ Rafaqat Rashid, ${ }^{\mathrm{F}}$ \\ Salman Waqar ${ }^{\mathrm{G}}$ and Nazim Ghouri ${ }^{\mathrm{H}}$
}

Fasting in the month of Ramadan is an obligatory act for healthy adult Muslims. It requires abstinence from food and drink from dawn to sunset. Although there are exemptions from fasting, many patients are keen to fulfil what they see as a religious obligation, even if this may be against medical advice in some cases. Solid organ transplant (SOT) recipients often ask healthcare professionals for advice on fasting. Studies on the effect of fasting in transplant patients have all been done in the Middle East and North Africa where the average fasting duration is between 12 and 14 hours. In comparison, in temperate regions in the summer, fasting duration can be as long as 20 hours. Fasting when patients have to take immunosuppression 12 hours apart with little time variation poses unique challenges. In this review, current literature is reviewed, and a decision-making tool has been developed to assist clinicians in discussing the risks of fasting in transplant recipients, with consideration also given to circumstances such as the COVID-19 pandemic.

Our review highlights that SOT recipients wishing to fast should undergo a thorough risk assessment, ideally 3 months before Ramadan. They may require medication changes and a plan for regular monitoring of graft function and electrolytes in order to fast safely. Recommendations have been based on risk tiers (very high risk, high risk and low/moderate risk) established by the International Diabetes Federation and the Diabetes and Ramadan International Alliance. Patients in the 'very high risk' and 'high risk' categories should be encouraged to explore alternative options to fasting such as winter fasting

Authors: ${ }^{A}$ consultant transplant nephrologist, University Hospitals Coventry and Warwickshire NHS Trust, UK, and honorary clinical lecturer, University of Leicester, Leicester, UK; ${ }^{\mathrm{B}}$ consultant nephrologist, University Hospitals Coventry and Warwickshire NHS Trust, UK; ${ }^{C}$ consultant in kidney medicine and kidney transplantation,

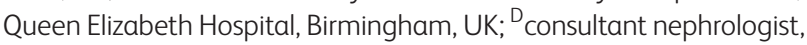
The Royal London Hospital, London, UK; ${ }^{E}$ consultant transplant surgeon, University Hospitals of Leicester NHS Trust, Leicester, UK; F general practioner and Islamic scholar, Al Balagh Academy, UK; ${ }^{G}$ academic research fellow, University of Oxford, Oxford, UK; ${ }^{H}$ honorary clinical senior lecturer, University of Glasgow, Glasgow, UK, and consultant physician in diabetes, endocrinology and general medicine, Queen Elizabeth University Hospital, Glasgow, UK or Fidyah. Those in the 'low/moderate' category may be able to cautiously fast with guidance from their clinician. Prior to the commencement of Ramadan, all patients must receive up-to-date education on sick-day rules, instructions on when to terminate their fast or abstain from fasting.

KEYWORDS: fasting, heart, kidney, liver, lung, Ramadan. transplant

DOI: 10.7861/clinmed.2021-0250

\section{Introduction}

Fasting in Ramadan is an obligatory act upon all healthy adult Muslims. ${ }^{1}$ Fasting requires abstinence of any oral intake including food, drink and medications from dawn to sunset. However, those who are ill or have underlying health conditions are exempt from fasting. Despite having valid exemptions, many patients are keen to fulfil what they see as a religious obligation, even if this may be against medical advice. ${ }^{2,3}$ Timing of Ramadan is based on the lunar calendar. Ramadan falls 11 days earlier annually and over a 33-year period passes through all four seasons, leading to shorter fasts in winter and longer in the summer months in temperate regions - stretching up to 20 hours in the summer and as short as 10 hours in winter in the UK. ${ }^{4}$

In comparison to dialysis, transplantation offers better survival and quality of life (QOL) for those suitable to undergo the procedure. Patients expect an improvement in their QOL following transplantation. ${ }^{5}$ One aspect of QOL for Muslim patients may be their ability to fulfil their religious obligations. Indeed, many transplant recipients ask their clinicians for permission to fast. ${ }^{6}$

A major concern with fasting, especially in hot weather, is the potential for dehydration and the attendant risk of acute kidney injury resulting in potentially irreversible loss of renal function. ${ }^{6}$ Furthermore, prolonged periods of fasting during the summer months would prevent patients from taking medication at prescribed intervals, especially if these had to be taken 12 hours apart. Immunosuppression taken at inconsistent intervals can lead to variable drug levels and consequent risk of graft loss; hence it is vital for immunosuppressive medications to be taken at prescribed intervals. ${ }^{7}$ Studies have shown that a significant proportion of patients who fast do not adhere to their medication as prescribed, increasing risk of rejection. ${ }^{8,9}$ Whether or not these theoretical risks are borne out in reality have been 
the subject of several single-centre trials and a recent metaanalysis. $^{10}$

Between April 2019 and March 2020, 23.7\% of kidney transplant recipients (KTRs) in the UK were identified as Asian and $13.4 \%$ were from the Black community. ${ }^{11}$ Although data on their religious belief are not available, UK demographic data would suggest that $43.4 \%$ of British Asians and a proportion of Black British people are Muslims. $^{12}$

Given the lack of formal guidance and expert consensus, the aim of this review is to provide an up-to-date appraisal of current literature and provide healthcare professionals (HCPs) with an easy decision-making tool that can educate patients and guide discussions relating to the risks of fasting in patients with solid organ transplants (SOTs).

\section{Methods}

We undertook a narrative review of current literature on Ramadan fasting in patients with SOT. PubMed and Google Scholar databases were searched for studies using terms 'Ramadan', 'fasting', 'kidney', 'liver', 'heart', 'pancreas', 'small bowel', 'multi organ' and 'transplant' in various combinations. All retrieved articles were considered for inclusion. Existing reviews of literature on these topics were also reviewed for references where appropriate. No language or study restrictions were applied but for practical considerations only English language articles were reviewed. Retrieved articles ranged from systematic reviews, observational studies and narrative reviews. While the focus in this review relates to effect of fasting in SOT recipients, fasting during the COVID-19 pandemic is also briefly discussed.

The recommendations are meant to be informative and do not form a directive. Treating physicians need to take into consideration the patient's wishes and individual circumstances. Ultimately, the decision to fast or otherwise rests with the patient with the guidance and recommendations to facilitate the process and to make fasting as safe as possible if undertaken.

We utilised a three-tiered risk assessment based on the widely used criteria established by the International Diabetes Federation and the Diabetes and Ramadan (IDF-DAR) international alliance. ${ }^{13}$ Such a framework has been utilised by other related specialities and conditions including adrenal insufficiency and chronic kidney disease (CKD), including relevant 'sick-day rules' advice. ${ }^{14,15}$ Recommendations in Fig 1 can be used by HCPs to assign a risk level and provide fasting advice accordingly. ${ }^{16}$ The recently published 2021 IDF-DAR Ramadan guidelines introduced a three-tier risk assessment based on an individualised scoring rubric. ${ }^{17}$ However, this has not yet been validated and is based on physician opinion from an online survey with limited evidence

\begin{tabular}{|c|c|c|}
\hline Risk level & Patient categories & Advice summary \\
\hline Very high risk $^{a}$ & $\begin{aligned} &> \text { Solid organ transplant recipients who } \\
& \text { underwent a transplant in the last } 12 \text { months } \\
&>\text { Patients on twice-daily formulations of } \\
& \text { immunosuppression } \\
&>\text { Pregnant transplant patients } \\
&>\text { Transplant patients diagnosed with post- } \\
& \text { transplant diabetes mellitus requiring } \\
& \text { twice-daily oral hypoglycaemics or insulin } \\
& \text { treatment } \\
&>\text { Kidney transplant recipients with reduced } \\
& \text { kidney function (eGFR <30 mL/min) } \\
&>\text { Patients with unstable graft function, } \\
& \text { recent rejection episodes and opportunistic } \\
& \text { infections } \\
&>\text { Liver transplant recipients with unstable graft } \\
& \text { function, decompensated liver disease or } \\
& \text { evidence of cirrhosis on biopsy } \\
&>\text { Patients with moderate to severe frailty }\end{aligned}$ & Must not fast \\
\hline High risk & $\begin{array}{l}\text { Kidney transplant recipients with reduced } \\
\text { graft function (eGFR 30-60 mL/min) } \\
>\text { Heart, lung, liver, small bowel, pancreas } \\
\text { and multiorgan transplant recipients with } \\
\text { reduced graft function } \\
>\text { Patients at risk of dehydration due to fluid } \\
\text { restriction requirements, need for diuretics } \\
\text { or if they would be unable to meet their } \\
\text { daily fluid intake requirement set by their } \\
\text { transplant team } \\
>\text { Patients with mild frailty }\end{array}$ & Should not fast \\
\hline $\begin{array}{l}\text { Moderate/ } \\
\text { low risk }\end{array}$ & $\begin{array}{l}\text { Transplant patients not in the above categories. } \\
\text { We would advise patients to discuss the } \\
\text { suitability of fasting and monitoring necessary } \\
\text { with their relevant transplant teams }\end{array}$ & Follow medical advice \\
\hline
\end{tabular}

Fig 1. Key practice implicationscategorising risk of complications. aThe clinical risks of fasting in SOT recipients can include dehydration leading to graft dysfunction, rejection due to variable immunosuppression drug levels, hospitalisation, changes in blood pressure, fluid overload and graft loss. ${ }^{b}$ Frailty as determined by a frailty score such as the Rockwood Clinical Frailty Scale. 
Fig 2. Decision-making pathway when a patient wishes to fast during Ramadan.

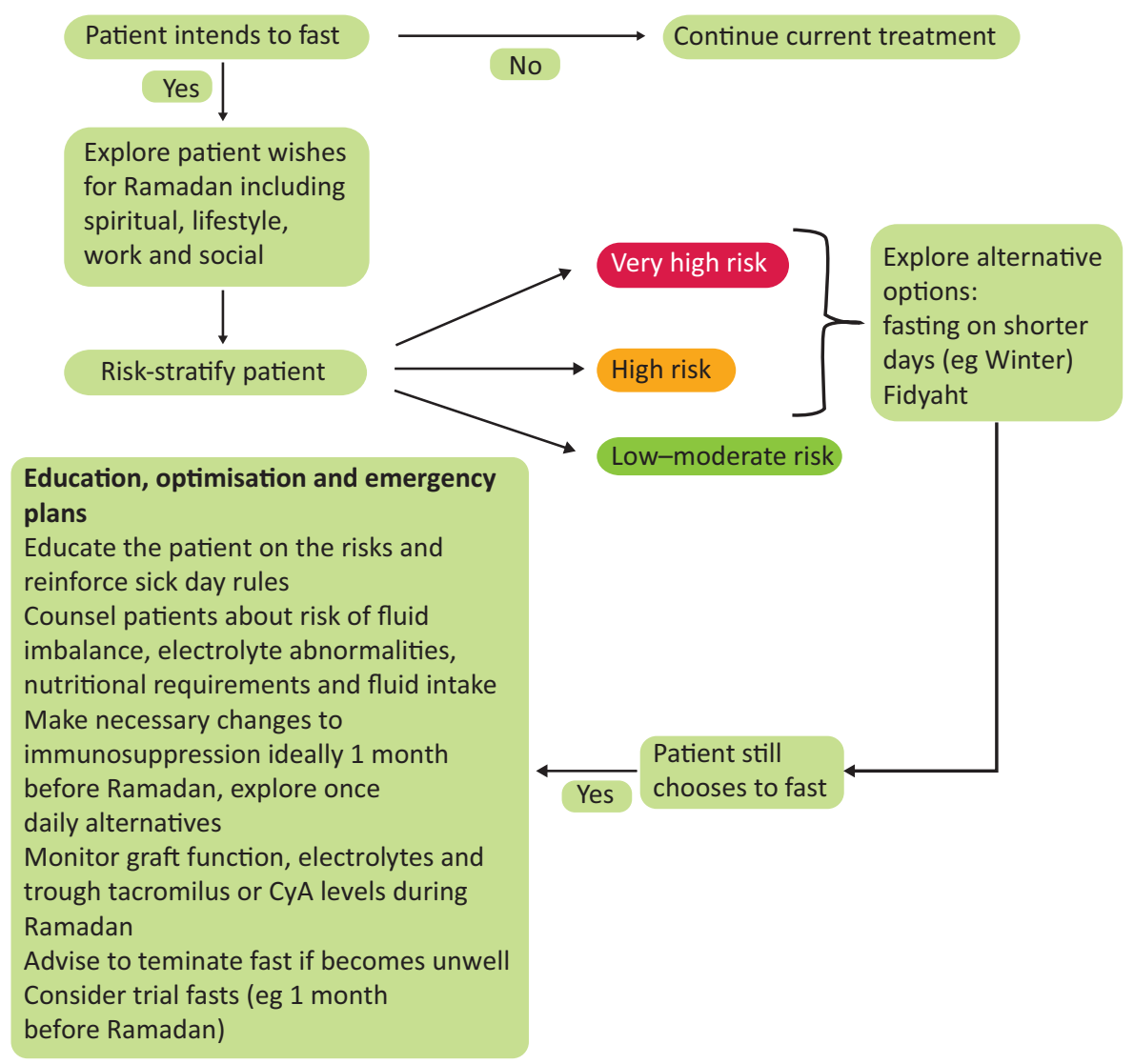

base, though it is a welcome move. As such, it is yet unclear if this approach is preferable to the previous model. ${ }^{18}$ We therefore relied on their earlier well-established risk stratification approach, but as more evidence emerges in this area, a scoring system could be considered. Moreover, the justification for the new scoring system was that the earlier system was not flexible; however, in our guide, we have proposed a patient-centred approach, discussed alternatives to fasting, and outlined guidance to support those in the high-risk categories who may choose to fast despite medical advice (Fig 2).

\section{Results}

\section{Current evidence}

The effect of fasting on SOT is limited to a few studies in KTRs supplementary material S1 and two studies in liver transplant recipients (LTRs) (Table 1).

\section{Kidney transplant}

A recent meta-analysis that included eight studies with a total of 549 patients showed no statistically significant difference in either glomerular filtration rate (GFR) $(70.1 \pm 9.1 \mathrm{vs} 68.5 \pm 7.5 \mathrm{~mL} /$ min, $p=0.6)$ or serum creatinine $(\mathrm{SCr})(105.3 \pm 8.8$ and $106.1 \pm$ $6.0 \mu \mathrm{mol} / \mathrm{L}, \mathrm{p}=0.47$ ) measured before the period of fasting and at different time points after Ramadan. No significant differences in systolic and diastolic blood pressures were found. However, in three studies where there was a comparator group of non-fasting individuals, a difference in eGFR $(-0.13 \pm 1.2 \mathrm{~mL} / \mathrm{min}$ in those who fasted vs $4.2 \pm 4.6 \mathrm{~mL} / \mathrm{min}$ in those who did not; $p=0.039$ ) was found. A funnel plot demonstrated publication bias due to the limited number of studies and systematic heterogeneity. All studies included in this meta-analysis were from five countries in the Middle East and North Africa where the fasting time varied between 12 and 14 hours. $^{6}$

A single-centre observational cohort study comparing fasting and non-fasting KTRs showed no difference in GFR between groups or within the fasting group before and 6 months after Ramadan (before fasting $75.6 \pm 29.2$ and $65.9 \pm 25.9 \mathrm{~mL} / \mathrm{min}$ $(p=0.1), 6$ months after fasting $77.2 \pm 29.7$ and $64.1 \pm 29 \mathrm{~mL} / \mathrm{min}$ $(p=0.21))^{21}$

Another cohort study from Saudi Arabia of 35 patients looked at effects of repeated fasting after three periods of Ramadan and did not find any difference in graft function, mean arterial pressure or albuminuria in fasters compared to non-fasters in linear regression models adjusting for confounders. However, not all relevant confounders such as immunological risk, immunosuppression and rejection episodes were adjusted for. In the fasting group, no change in ciclosporin $\mathrm{A}(\mathrm{CyA})$ or tacrolimus level was noted before and after fasting $(304.5 \mathrm{ng} / \mathrm{mL}$ and $200 \mathrm{ng} / \mathrm{mL}(\mathrm{p}=0.153)$ and $7.3 \mathrm{ng} / \mathrm{mL}$ and $6.4 \mathrm{ng} / \mathrm{mL}(\mathrm{p}=0.327)$, respectively). ${ }^{22}$ No rejection episodes occurred in the fasting group; majority of the patients were more than 1-year post transplant, and five were within 1-year post transplant. ${ }^{23,24}$ In a recent paper from our group, we have developed a decisionmaking tool for CKD patients intending to fast; some of this guidance would also be applicable for KTRs with CKD. ${ }^{15}$ 
Table 1. Studies in liver transplant recipients

\begin{tabular}{|c|c|c|c|c|c|c|}
\hline Author & Year & $\begin{array}{l}\text { Number of } \\
\text { patients }\end{array}$ & $\begin{array}{l}\text { Time post } \\
\text { transplant } \\
\text { (mean or } \\
\text { median) }\end{array}$ & Immunosuppression & $\begin{array}{l}\text { Outcome } \\
\text { measure }\end{array}$ & Result \\
\hline Montasser $^{19}$ & 2020 & $\begin{array}{l}45,84.4 \% \\
\text { males }\end{array}$ & $\begin{array}{l}51.6 \pm 28 \\
\text { months }\end{array}$ & $\begin{array}{l}20 \text { patients were on conventional } \\
\text { tacrolimus, five patients were } \\
\text { on reduced-dose tacrolimus + } \\
\text { everolimus, four patients were on a } \\
\text { once-daily tacrolimus, } 14 \text { patients } \\
\text { were on CyA } \pm \text { mycophenolic acid } \\
\text { derivatives, and two patients were } \\
\text { on a CNI-free regimen of Myfortic + } \\
\text { everolimus. Patients taking tacrolimus } \\
\text { were instructed to either change to } \\
\text { a prolonged-release capsule once- } \\
\text { daily dose for better compliance, } \\
\text { or take two-thirds of their dose of } \\
\text { conventional tacrolimus at dawn } \\
\text { and one-third at sunset on an empty } \\
\text { stomach } \\
\text { For patients on CyA, they were } \\
\text { instructed to take two-thirds of the } \\
\text { dose at dawn and one-third at sunset }\end{array}$ & $\begin{array}{l}\text { Renal and } \\
\text { liver function }\end{array}$ & $\begin{array}{l}\text { There was a significant } \\
\text { change in renal function } \\
\text { pre and post-Ramadan } \\
(1.1 \pm 0.2 \mathrm{vs} 1.25 \pm \\
0.27 \mathrm{mg} / \mathrm{dL}(\mathrm{p}=0.004)) \text {. } \\
\text { Thirty seven patients } \\
\text { completed fasting, five } \\
\text { stopped due to rise in } \\
\text { creatinine, three had } \\
\text { interrupted fasting. Liver } \\
\text { function, tacrolimus } \\
\text { and CyA levels were not } \\
\text { significantly different }\end{array}$ \\
\hline Derbala $^{20}$ & 2018 & $\begin{array}{l}96,58 \\
\text { were male }\end{array}$ & $\begin{array}{l}>1 \text { year } \\
\text { post } \\
\text { transplant }\end{array}$ & Tacrolimus & $\begin{array}{l}\text { Renal } \\
\text { and liver } \\
\text { function, } \\
\text { tacrolimus } \\
\text { level }\end{array}$ & $\begin{array}{l}\text { Significant differences } \\
\text { were found in } \\
\text { albumin, total protein, } \\
\text { cholesterol, creatinine, } \\
\text { haemoglobin and } \\
\text { platelet count during } \\
\text { Ramadan when } \\
\text { compared to before } \\
\text { and after Ramadan, } \\
\text { all above measured } \\
\text { parameters were lower } \\
\text { during Ramadan }\end{array}$ \\
\hline
\end{tabular}

\section{Liver transplant}

Two studies have reported on the effects of fasting in LTR. A prospective study of 45 patients in Egypt from 2018 included low-risk, motivated patients, at least a year post transplant with normal liver and renal function, no rejection episodes in the preceding 6 months and normal cardiac function. Those within a year post transplant, requiring anti-coagulation for Budd-Chiari syndrome or hepatic artery, portal vein stent and those with creatinine clearance $<60 \mathrm{~mL} / \mathrm{min}$ at enrolment were excluded from the study. Immunosuppression regime was modified such that recipients on twice-daily tacrolimus either converted to once-a-day formulation or were advised to take two-thirds of the dose at dawn and one-third at sunset. Similarly, those on CyA were also asked to split the dose. Mycophenolate mofetil (MMF) was continued and taken at fixed time points when patients were able to eat and drink. Participants were followed up weekly. There was a significant rise in $\mathrm{SCr}$ post-Ramadan compared to pre-Ramadan $(1.1 \pm 0.2 ; 1.25 \pm 0.27 \mathrm{mg} / \mathrm{dL} ; \mathrm{p}=0.004)$. Five patients were advised to stop fasting due to a rise in $\mathrm{SCr}$ during follow-up. Their renal function returned to baseline with increased fluid intake. No change in liver function, potassium levels or CyA/tacrolimus trough levels were seen. ${ }^{19}$

A retrospective observational cohort study from Qatar reported on safety of fasting in LTR during Ramadan in 2017. Ninety-six patients were included, and biochemical and biopsy results were collected 4 weeks pre- and post-Ramadan and every 2 weeks during Ramadan. All patients had normal synthetic liver function with no features of decompensation or cirrhosis on liver biopsy. Fasting patients were compared to a non-fasting control group. No change in model for end-stage liver disease (MELD) score was seen; there was also no significant change in liver function in the fasting group. It is not clear whether immunosuppression was modified, no difference in tacrolimus trough level was seen between groups $(p=0.9)$. However, in the fasting group, mean tacrolimus levels during fasting were slightly lower compared to levels pre- and post-Ramadan $(4.8 \mathrm{ng} / \mathrm{mL}$ pre, $3.5 \mathrm{ng} / \mathrm{mL}$ during and $4.9 \mathrm{ng} / \mathrm{mL}$ post; $p=0.01$ ), these are within therapeutic target levels of 3 to $8 \mathrm{ng} / \mathrm{mL} .{ }^{25}$ Rejection episodes or hospitalisation rates were not reported. ${ }^{20}$

No studies were found in other SOT recipients. 


\section{Discussion on existing data}

All studies except two examining the association of the effect of fasting on graft function were done in KTRs. Moreover, these studies were all undertaken at centres in the Middle East or North Africa where the time of fast varies between 12 and 14 hours. All studies were observational in nature with small sample sizes. The majority of recipients included in these studies had good reported baseline graft function of $>60 \mathrm{~mL} / \mathrm{min}$. The effect of fasting in transplant recipients with poorer graft function is unknown.

The study by Hejaili et al looking at the effect of repeated fasting reported a drop in eGFR at 18-month follow-up in those with baseline eGFR $>75 \mathrm{~mL} / \mathrm{min}$ in the fasting and non-fasting groups. Interestingly, such a change was not noted in the eGFR $<45 \mathrm{~mL} / \mathrm{min}$ or 45 to $75 \mathrm{~mL} / \mathrm{min}$ groups. ${ }^{26}$ Other studies with a comparator group did not show a difference in GFR. Any difference in graft function in fasting and non-fasting individuals, therefore, is not a universal or consistent finding. A study by Said et al reported two cases of acute rejection ${ }^{27}$; none of the other studies reported any cases of acute rejection supplementary material S1.

In the study from Egypt on LTR, fasting patients had a significant rise in $\mathrm{SCr}$, requiring patients to stop fasting after which renal function returned to baseline. One study explored the effect of annual repeated fasting with no demonstrable deterioration in graft function over time. Of the studies that reported immunosuppression levels in KTRs, no difference in immunosuppression drug levels was seen. In LTR, the study by Montasser et al showed no betweengroup difference in trough tacrolimus levels. However, within the fasting group, there was a small but statistically significant rise in creatinine during Ramadan. ${ }^{19}$

The clinical risks of fasting in SOT recipients can include dehydration leading to graft dysfunction, rejection due to variable immunosuppression drug levels, hospitalisation, changes in blood pressure, and fluid overload. Although studies have only focused on kidney and liver transplant recipients, the importance of compliance with immunosuppression to maintain graft function and relevance of hydration and fluid management is common to all SOT recipients. ${ }^{28,29}$ Graft loss can lead to return to dialysis or need for another organ transplant in some. Given the observational nature of the studies, there exists a risk of selection bias and residual confounding. In addition, the heterogeneous nature of the studies with different endpoints and reporting of outcomes mean direct comparisons cannot be made.

\section{Religious considerations on fasting and recommendations pertaining to solid organ transplant recipients}

As a general rule, any form of nutrition and medication that involves administration via a mucosal route, that is, oral, nasal or rectal, is not permitted for a person observing fast. ${ }^{30}$ Use of topical, intramuscular, subcutaneous medications such as insulin is permitted and do not invalidate the fast. ${ }^{2}$

It is a traditional practice to have two meals over the 24 -hour period - Suhoor (also known as Sehri), the pre-dawn meal, and Iftaar, the sunset meal. It is also worth noting that fasting has been associated with beneficial changes to general well-being. ${ }^{3}$ Ultimately, the decision to fast or otherwise rests with the individual concerned. Islam permits, and indeed supports, those with appropriate ailments to terminate the fast or be exempted from fasting. The two main alternatives to fasting are:
$>$ making up the missed fast when health permits them to do so - either when the illness is no longer present, such as in acute illness; or when health is not worsened by fasting at another point in time (eg in the winter) in relation to chronic illness ${ }^{3}$

$>$ an exemption from fasting in those whose illness will not permit them to keeping fasts indefinitely, this being replaced by a requirement to feed the poor, known as Fidyah.

Appropriate ailments that enable the exemptions above can also include old age and frailty, or a stable condition that can be exacerbated and adversely affect the patient as a result of fasting. ${ }^{1,4}$ This also includes abstaining from the use of medication which increases the risk of decompensation of chronic but stable health conditions. Arriving at such decisions is based on the premise that the ailment will worsen, or recovery be delayed or impaired by fasting, or a substantial fear that either may occur. This can be determined by prior experience of fasting with the ailment, common knowledge that this can happen, or on the advice/opinion of an appropriate HCP. 1 Muslims are encouraged, if they have any uncertainty regarding the various dispensations, to seek counsel from a trusted religious authority.

Despite valid exemptions, there is an intense desire to fast during this month even among those who are considered high risk, for example, the elderly and multimorbid. ${ }^{3,31}$ A more detailed exposition pertaining to the religious obligation of fasting and practical considerations in relation to health and illness and in those with diabetes or CKD have been published elsewhere.,15 IDF-DAR convened recognised experts to develop practical guidelines on the management of diabetes during Ramadan. The guidelines were developed following literature review and on expert consensus where evidence did not exist. Guidance is based on three risk categories - 'very high risk' patients must not fast, 'high risk' patients should not fast and those in the 'low/ moderate' category should take guidance from their clinician. The guidance was approved by religious scholars. ${ }^{13}$ We have developed a decision-making tool based on the principles of the IDF-DAR risk tiers that HCPs can use while counselling patients regarding the risk of complications if they were to fast. Consensus was sought from transplant physicians and surgeons involved in the care of Muslim patients, and from a religious scholar while developing our guidance. Patients in the 'very high risk' and 'high risk' tiers should receive medical advice that they 'must not fast' and 'should not fast,' respectively. Those in the 'low/moderate risk' category may be able to fast on advice from their physician, considered along with the ability of the individual to tolerate the fast (see Fig 2). During counselling, patients and HCPs are best to consider the alternatives discussed below, which may be safer options for some patients.

\section{Trial fasting}

Following any necessary medication changes, patients could consider a trial of fasting for a few days prior to start of Ramadan (we suggest within the month prior) with close monitoring of immunosuppression drug levels and graft function to establish safety and tolerability.

\section{Winter fasting}

In temperate regions, time period between dawn and dusk can be as short as 8 to 10 hours in the winter; and for many patients, 
this may be tolerable and safely achievable without changes in medication. ${ }^{4}$

It is also important to reinforce sick-day rules on which medications to stop during an acute illness, examples include ACE-I, ARB and diuretics.

\section{Medication switch}

Immunosuppression usually consists of a calcineurin inhibitor (CNI), anti-proliferative agent such as MMF - which are usually taken twice daily - and prednisolone. Some SOT recipients may also be on a once-daily mammalian target of rapamycin inhibitor (mTORi) such as sirolimus. Once-daily formulations of $\mathrm{CNI}^{32}$ are widely used with a good evidence base for non-inferiority. ${ }^{33}$ Similarly, azathioprine is a once-daily anti-proliferative and may be an acceptable alternative in low immunological risk patients in place of MMF. ${ }^{34,35}$ Clinicians should consider switching patients wishing to fast to these alternative treatment regimens in order to avoid drug level variability. Medication switching should be done sequentially and at least 3-6 months before the onset of Ramadan in order to achieve therapeutic target drug levels and assess for graft rejection or unacceptable side effects. Patients should be provided with appropriate education and support, including counselling regarding sick-day rules and risks, prior to and during any process of making changes to medication.

\section{Fluid balance}

Dehydration is a risk factor for acute kidney injury, ${ }^{36}$ KTRs should be counselled on fluid and nutritional requirements while fasting; good practice would be for patients to maintain a daily diary of weight and blood pressure and to be given targets of when to seek help with their treating physician, in order for adjustments to be made to antihypertensives or for graft function monitoring.

\section{Specific considerations in the context of COVID-19}

Organ transplant recipients are at high risk of SARS-CoV-2 infection causing COVID-19, given their immunosuppressed state, ${ }^{37}$ and should follow local government guidance on shielding. The effect of one dose of COVID-19 vaccination has been suboptimal and whether the second dose provides improved protection remains to be seen. ${ }^{38}$ Whether fasting would further increase the baseline risk of organ transplant recipients to COVID-19 is unknown.

\section{Conclusion}

Data around the safety and feasibility of SOT recipients observing the Ramadan fast are scarce but stable KTRs may be able to fast with close monitoring. Similarly, select liver and other SOT recipients intending to fast may be able to do so and would have to be counselled about the risk of variable immunosuppression drug levels, rejection, graft dysfunction and dehydration. Well-designed observational studies with large sample sizes or randomised controlled trials in SOT recipients - specifically heart, liver and pancreas recipients - are urgently needed to address the gap in knowledge.

\section{Supplementary material}

Additional supplementary material may be found in the online version of this article at www.rcpjournals.org/clinmedicine: S1 - Studies in kidney transplant recipients.

\section{References}

1 Ghouri N, Hussain S, Mohammed R et al. Diabetes, driving and fasting during Ramadan: the interplay between secular and religious law. BMJ Open Diabetes Res Care 2018;6:e000520.

2 Abolaban H, Al-Moujahed A. Muslim patients in Ramadan: a review for primary care physicians. Avicenna J Med 2017;7:81-7.

3 Salti I, Bénard E, Detournay B et al. A population-based study of diabetes and its characteristics during the fasting month of Ramadan in 13 countries: results of the epidemiology of diabetes and Ramadan 1422/2001 (EPIDIAR) study. Diabetes Care 2004:27:2306-11.

4 Ghouri N, Gatrad R, Sattar N, Dhami S, Sheikh A. Summer-winter switching of the Ramadan fasts in people with diabetes living in temperate regions. Diabet Med 2012;29:696-7.

5 Smith D, Loewenstein G, Jepson C, Jankovich A, Feldman H, Ubel P. Mispredicting and misremembering: patients with renal failure overestimate improvements in quality of life after a kidney transplant. Health Psychol 2008;27:653-8.

6 Binsalih S, Al Sayyari RA, Sheikho M, Hejaili FF, Al Sayyari AA. Effect of fasting the whole month of Ramadan on renal function among Muslim patients with kidney transplant: a meta-analysis. Exp Clin Transplant 2019;17:588-93.

7 Rodrigo E, Segundo DS, Fernández-Fresnedo G et al. Withinpatient variability in tacrolimus blood levels predicts kidney graft loss and donor-specific antibody development. Transplantation 2016;100:2479-85

8 Karaağaoğlu N, Yücecan S. Some behavioural changes observed among fasting subjects, their nutritional habits and energy expenditure in Ramadan. Int J Food Sci Nutr 2000;51:125-34.

9 Aslam M, Healy MA. Compliance and drug therapy in fasting Moslem patients. J Clin Hosp Pharm 1986;11:321-5.

10 Bragazzi NL. Ramadan fasting and chronic kidney disease: a systematic review. J Res Med Sci 2014;19:665-76.

11 NHS Blood and Transplant. Annual activity report, 2019. www.odt. nhs.uk/statistics-and-reports/annual-activity-report/ [Accessed 12 August 2021].

12 Office for National Statistics. Ethnicity and religion by age. ONS, 2015. www.ons.gov.uk/aboutus/transparencyandgovernance/ freedomofinformationfoi/ethnicityandreligionbyage [Accessed 12 August 2021].

13 Hassanein M, Al-Arouj M, Hamdy O et al. Diabetes and Ramadan: practical guidelines. Diabetes Res Clin Pract 2017;126:303-16.

14 Hussain S, Mohammed R, Meeran K, Ghouri N. Fasting with adrenal insufficiency: practical guidance for healthcare professionals managing patients on steroids during Ramadan. Clin Endocrinol (Oxf) 2020:93:87-96.

15 Malik S, Bhanji A, Abuleiss $\mathrm{H}$ et al. Effects of fasting on patients with chronic kidney disease during Ramadan and practical guidance for healthcare professionals. Clin Kidney ] 2021;14:1524-34.

16 Waqar S, Ghouri N. Managing Ramadan queries in COVID-19. BJGP Open 2020;4:bjgpopen20X101097.

17 Diabetes and Ramadan: Practical guidelines 2021, 2021. www. daralliance.org/daralliance/idf-dar-practical-guidelines-2021/ [Accessed 12 August 2021].

18 Ghouri N, Hussain S, Ahmed SH et al. Changing how we risk-categorise in Ramadan: Does the IDF-DAR scoring system achieve the requirements for people with diabetes internationally? Diabetes Res Clin Pract 2021:175:108835. 
19 Montasser IF, Dabbous H, Sakr MM et al. Effect of Ramadan fasting on Muslim recipients after living donor liver transplantation: a single center study. Arab J Gastroenterol 2020;21:76-9.

20 Derbala M, Elbadri M, Amer A et al. Safety and deleterious effect of fasting Ramadan in liver transplant recipients. J Gastroenterol Metabol 2018:1:301.

21 Qurashi S, Tamimi A, Jaradat M, Al Sayyari A. Effect of fasting for Ramadan on kidney graft function during the hottest month of the year (August) in Riyadh, Saudi Arabia. Exp Clin Transplant 2012;10:551-3.

22 Ghalib M, Qureshi J, Tamim H et al. Does repeated Ramadan fasting adversely affect kidney function in renal transplant patients? Transplantation 2008;85:141-4.

23 Rouhani MH, Azadbakht L. Is Ramadan fasting related to health outcomes? A review on the related evidence. J Res Med Sci 2014;19:987-92

24 Argani H, Mozaffari S, Rahnama B, Rahbani M, Rejaie M, Ghafari A. Evaluation of biochemical and immunologic changes in renal transplant recipients during Ramadan fasting. Transplant Proc 2003;35:2725-6

25 Millson C, Considine A, Cramp ME et al. Adult liver transplantation: UK clinical guideline - part 2: surgery and post-operation. Frontline Gastroenterol 2020;11:385-96.

26 Hejaili F, Qurashi S, Binsalih S, Jaradt M, Al Sayyari A. Effect of repeated Ramadan fasting in the hottest months of the year on renal graft function. Nephrourol Mon 2014;6:e14362.

27 Said T, Nampoory MR, Haleem MA et al. Ramadan fast in kidney transplant recipients: a prospective comparative study. Transplant Proc 2003;35:2614-6.

28 Kuypers DRJ. Intrapatient variability of tacrolimus exposure in solid organ transplantation: a novel marker for clinical outcome. Clin Pharmacol Ther 2020;107:347-58.

29 Pollock-Barziv SM, Finkelstein Y, Manlhiot C et al. Variability in tacrolimus blood levels increases the risk of late rejection and graft loss after solid organ transplantation in older children. Pediatr Transplant 2010;14:968-75.
30 Rashid R. Part 2-what invalidates fasting related to body cavities. www.academia.edu/43158103/PART_2_WHAT_INVALIDATES_ FASTING_RELATED_TO_BODY_CAVITIES2020

31 NasrAllah MM, Osman NA. Fasting during the month of Ramadan among patients with chronic kidney disease: renal and cardiovascular outcomes. Clin Kidney J 2014;7:348-53.

32 Staatz CE, Tett SE. Clinical pharmacokinetics of once-daily tacrolimus in solid-organ transplant patients. Clin Pharmacokinet 2015;54:993-1025.

33 Vadcharavivad S, Saengram W, Phupradit A, Poolsup N, Chancharoenthana W. Once-daily versus twice-daily tacrolimus in kidney transplantation: a systematic review and meta-analysis of observational studies. Drugs 2019;79:1947-62.

34 Bansal SB, Saxena V, Pokhariyal S et al. Comparison of azathioprine with mycophenolate mofetil in a living donor kidney transplant programme. Indian J Nephrol 2011;21:258-63.

35 Moini M, Schilsky ML, Tichy EM. Review on immunosuppression in liver transplantation. World ] Hepatol 2015;7:1355-68.

36 Roncal-Jimenez C, Lanaspa MA, Jensen T, Sanchez-Lozada LG, Johnson RJ. Mechanisms by which dehydration may lead to chronic kidney disease. Ann Nutr Metab 2015;66:10-3.

37 Lum E, Bunnapradist S, Multani A et al. Spectrum of coronavirus disease 2019 outcomes in kidney transplant recipients: a singlecenter experience. Transplant Proc 2020;52:2654-8.

38 Boyarsky B], Werbel WA, Avery RK et al. Immunogenicity of a single dose of SARS-CoV-2 messenger RNA vaccine in solid organ transplant recipients. JAMA 2021;325:1784-6.

Address for correspondence: Dr Shafi Malik, Department of Nephrology, University Hospital Coventry, Clifford Bridge Rd, Coventry CV2 2DX, UK.

Email: shafi.malik@uhcw.nhs.uk

Twitter: @shafisara 